\title{
O dispositivo de Numeramentalidade: uma ferramenta conceitual, metodológica e analítica de inspiração foucaultiana
}

\author{
Renata Sperrhake ${ }^{1}$
}

Samuel Edmundo Lopez Bello²

\section{Resumo}

O presente artigo apresenta o que denominamos do Dispositivo de Numeramentalidade, mostrando sua potencialidade como ferramenta conceitual, metodológica e analítica para o campo das Ciências Humanas e da Educação. A fundamentação teórica principal são os estudos do filósofo francês Michel Foucault. Partimos de uma revisão sobre o conceito de dispositivo para mostrar como a Numeramentalidade pode ser entendida como: 1) um dispositivo histórico; 2) uma grade analítica e 3) um programa de pesquisa. Abordamos também o que chamamos de "efeito amarra", focalizando os processos de subjetivação engendrados pelo referido dispositivo. Por fim, salientamos a potencialidade do conceito para a análise de práticas envolvendo números, quantificações, medidas e classificações, entre outras.

Palavras-chave: Dispositivo; Numeramentalidade; Michel Foucault.

El Dispositivo de Numeramentalidad: una herramienta conceptual, metodológica y analítica de inspiración foucaultiana

\section{Resumen}

El presente artículo presenta lo que denominamos el Dispositivo de Numeramentalidad, mostrando su potencialidad como herramienta conceptual, metodológica y analítica para el campo de las Ciencias Humanas y de la Educación. La fundamentación teórica principal son los estudios del filósofo francés Michel Foucault. Partimos de una revisión sobre el concepto de dispositivo para mostrar cómo la Numerabilidad puede ser entendida como: 1) un dispositivo histórico; 2) una cuadrícula analítica y 3) un programa de investigación. Abordamos también lo que llamamos "efecto amarra", enfocando los procesos de subjetivación engendrados por dicho dispositivo. Por último, subrayamos la potencialidad del concepto para el análisis de prácticas que involucran números, cuantificaciones, medidas, clasificaciones, entre otras.

Keywords: Dispositivo; Numeramentalidad; Michel Foucault.

\section{Considerações iniciais}

A paixão de trabalhar com Foucault tem como ponto de emergência o conjunto de estudos realizados pelo grupo de pesquisa CNPq-Praktiké, vinculado ao Programa de Pósgraduação em Educação da UFRGS, na tentativa de elucidar, num viés histórico-analítico, as relações existentes entre as práticas sociais e a produção de linguagens, saberes e sujeitos (JELINEK, BELLO, SANTOS, 2017). Igualmente, e pela compreensão relacional do poder-saber e

\footnotetext{
${ }^{1}$ Universidade Federal do Rio grande do Sul, Porto Alegre, renata.sperrhake@gmail.com

2 Universidade Federal do Rio grande do Sul, Porto Alegre, samuel.bello@ufrgs.br
}

Periódico Horizontes - USF - Itatiba, SP - Brasil - e019025 
das formas de Governo dentro daquilo que Foucault (2008), na obra "Segurança, Território e População" descreveu como Governamentalidade, é que viemos procurando compreender artes, racionalidades, saberes, regimes específicos de formas de pensar e agir em determinados momentos históricos e que estão envolvidos na produção de práticas e tecnologias, na produção de condutas de si e dos outros, no campo da Educação e mais especificamente na Educação Matemática. Essa governamentalidade que viemos discutindo nas nossas pesquisas tem se aproximado de um pensar sobre a produção de subjetividades dado que, formas de governo no âmbito do coletivo, apontam também para a constituição de determinados tipos de sujeitos no âmbito do individual.

Nesse sentido, e na conjunção da noção de Governamentalidade e de seus processos em práticas matemáticas escolares, no âmbito do poder-saber e da subjetivação, encontramos inspiração para criar o neologismo Numeramentalidade (BELLO, 2012a; BELLO; TRAVERSINI, 2011) como um conceito que designe a combinação entre artes de governar e as práticas de numerar, medir, contabilizar, seriar e que, num viés normativo, orientariam a produção enunciativa de práticas contemporâneas.

Da Numeramentalidade como criação conceitual (BELLO, 2012b) ampliamos e conduzimos sua enunciação também como dispositivo metodológico e analítico numa recente tese de doutorado (SPERRHAKE, 2016), o que nos permitiu analisar a constituição de práticas que colocam em funcionamento visibilidades e dizibilidades numéricas a fim de produzir saberes e conduzir condutas. É disso que se trata este artigo: produzir o sentido de Numeramentalidade como dispositivo e argumentar o porquê ele pode ser uma potente ferramenta conceitual, analítica e metodológica em Educação.

\section{O que é um dispositivo?}

Partindo dessa pergunta autores como Deleuze (1990), Moro Abadía (2003) e Agamben (2005) buscaram compreender a posição assumida pelo conceito de dispositivo na obra foucaultiana. Parece não ser fácil enunciar o que é, afinal, esse conceito. Apesar de seu uso extensivo no campo das ciências humanas desde que Foucault tratou do seu "dispositivo disciplinar" (2009) e do "dispositivo da sexualidade" (2011a, 2011c), carecemos, segundo Moro 
Abadía (2003), de enfoques mais reflexivos e abstratos a respeito da noção.

Mesmo considerando a "poligênese" do conceito de dispositivo, Moro Adabía (2003) aponta que os autores que escolhem trabalhar com essa ferramenta remetem ao trabalho de Foucault com grande frequência. "Dispositivos técnicos", "dispositivo estratégico", "dispositivos televisuais" (MORO ABADÍA, 2003), “dispositivo pedagógico da mídia” (FISCHER, 2002), "dispositivo da infantilidade" (CORAZZA, 2004), "dispositivo da maternidade" (MARCELLO, 2003; 2009), "dispositivo pedagógico da arte" (DALLA ZEN, 2011), “dispositivo psicogenético" (CAMINI, 2015), "dispositivo da intersetorialidade" (SANTAIANA, 2015), "dispositivo da antecipação da alfabetização" (CALDEIRA, 2016). Tais termos mostram a proliferação de usos do conceito e sua produtividade para se pensar um espaço de relações de saber-poder, no qual a análise das formas de produção e circulação do saber aliada às formas de condução das condutas de si e dos outros e às formas de subjetividades engendradas por esse jogo se faz necessária e potente.

Foucault estabelece o conceito de dispositivo argumentando que tal conceito amplia o de épistémè, utilizado nos seus primeiros trabalhos, especialmente em "As Palavras e as Coisas" (FOUCAULT, 2007) e "Arqueologia do Saber" (FOUCAULT, 2009). O dispositivo faz essa ampliação ao agregar à análise discursiva o eixo do poder e as práticas não discursivas, além de demandar uma análise genealógica. Por mais que haja uma definição do que seria o dispositivo, isto é, “[...] um conjunto decididamente heterogêneo que engloba discursos, instituições, organizações arquitetônicas, decisões regulamentares, leis, medidas administrativas, enunciados científicos, proposições filosóficas, morais, filantrópicas. Em suma, o dito e o não dito são os elementos do dispositivo" (FOUCAULT, 2011a, p.244), não podemos negar a complexidade que tal conceito carrega. Além disso, o dispositivo, compreendido como as próprias práticas culturais (e históricas) que relacionam poder e saber, possibilita a constituição de uma grade de análise (CORAZZA, 2004). A questão fundamental que fez com que um conceito como esse fosse necessário na analítica de Foucault foi:

[...] como localizar e compreender um conjunto de práticas coerentes que organizem a realidade social quando não se pode recorrer ao sujeito que a constituiu (ou a uma série de sujeitos observando essas práticas), a leis objetivas ou ao tipo de regras que Foucault acreditou serem alternativas evitadas? (DREYFUS; RABINOW, 2013, p.161).

Periódico Horizontes - USF - Itatiba, SP - Brasil - e019025 
Nesse sentido, com a desconstrução do sujeito da modernidade capaz de, através da razão, encontrar a verdade, e a suspensão das essencialidades, Foucault precisaria de algo que estabelecesse uma ligação entre as práticas (discursivas e não discursivas) de um tempo histórico. Entende-se, desse modo, que um dispositivo responde a uma urgência histórica e tem "uma função estratégica dominante" (FOUCAULT, 2011a, p.244). Se o dispositivo organiza e torna possível "algo", é porque "[...] simplesmente faz existir um espaço particular prévio em que esse 'algo' pode produzir-se” (PEETERS; CHARLIER, 1999, apud MORO ABADÍA, 2003, p.40). Um dispositivo limita e faz surgir certas práticas (discursivas ou não), ao mesmo tempo em que é sustentado por elas.

Entende-se o dispositivo como uma grande rede de relações que se estabelecem entre o dito e o não dito, e possui um caráter estratégico que entrelaça e faz funcionar a relação podersaber. A metáfora do "entrelaçar" funciona bem para tratar desse conceito, uma vez que diversos autores, especialmente Deleuze, tratam o dispositivo como uma rede, “[...] uma espécie de novelo ou meada, um conjunto multilinear" (DELEUZE, 1990, p.155). A multilinearidade do dispositivo compreende múltiplas linhas, de visibilidade, de enunciação, de força, de subjetivação, de ruptura, de fissura, de fratura, que se entrecruzam e se misturam (DELEUZE, 1990), variando suas posições. Marcello (2009) considera, a partir de Deleuze (1990), que as linhas do dispositivo dizem respeito aos três eixos ou dimensões do trabalho de Foucault:

O primeiro eixo diz respeito à produção do saber ou, ainda, à constituição de uma rede de discursos; o segundo, ao eixo que se refere ao poder (eixo, este, que indicaria as formas pelas quais, dentro do dispositivo, é possível determinar as relações e disposições estratégicas entre seus elementos); o terceiro eixo diz respeito à produção de sujeitos (MARCELLO, 2009, p.231).

Contudo é preciso destacar que existe uma diferença entre a produção de sujeitos como efeito de assujeitamentos e como efeito de processos de subjetivação. Ao se tratar desse terceiro eixo no primeiro sentido, o entendemos como o engendramento de uma produção discursiva do sujeito, como efeito do verdadeiro, ao passo que o segundo sentido aponta para a possibilidade de resistências e de fugas, para a produção de singularidades.

A leitura deleuziana do conceito de dispositivo o considera como uma "máquina de fazer ver e fazer falar" (DELEUZE, 1990, p.155), na qual há curvas de visibilidade e curvas de 
enunciação. O regime de luz de um dispositivo diz respeito à incidência e à distribuição do visível e do invisível, fazendo aparecer (ou não) um determinado objeto que não existiria sem o próprio dispositivo.

Outra característica do dispositivo está relacionada à ideia que ele traz de posição, a partir do que se compreende "[...] que os elementos que o compõem não são significativos em si mesmos senão que seu significado deriva de sua posição relativa dentro do conjunto" (MORO ABADÍA, 2003, p.33). Além disso, os elementos que compõem um dispositivo adquirem significados pela função que desempenham e pelo tipo de relação que estabelecem. Conta, ainda, com uma gama de técnicas, estratégias e táticas que fazem funcionar o poder. No entanto, a partir de Deleuze (1990), compreende-se que o dispositivo não se trata apenas de colocar em uma grade de análise a relação saber-poder; por se tratar de um conceito multilinear, opera-se, também, a produção de modos de subjetivação a partir dessa relação saber-poder. Apesar de haver essas ideias de posição e de função dos elementos no interior de um dispositivo, vale ressaltar que não devemos compreendê-lo como algo estanque. A característica da multilinearidade do conceito implica também em movimento, uma vez que essas linhas não param de se entrecruzar e produzir novos cruzamentos e novos "espaços descontínuos", pois "[...] trata-se de linhas que se bifurcam, de curvas que tangenciam regimes de saberes móveis e entrecruzados, ligados a configurações de poder e designados a produzir modos de subjetivação específicos" (MARCELLO, 2003, p.79).

Cabe destacar ainda o "engajamento entre dispositivos" (MARCELLO, 2009, p.235), que faz com que a existência de um dispositivo só seja possível pela sua articulação com outros de seu tempo. Nesse sentido, o movimento de "[...] pensar as estratégias e mecanismos pelos quais um dispositivo se atualiza na linguagem" (MARCELLO, 2009, p.235) também se faz nessa relação entre dispositivos, criando um grande aparato discursivo que, pela incidência das suas forças, produz modos de existência em um tempo histórico.

López (2011, p.47) considera que “o conceito de 'experiência' se encontra intimamente vinculado ao conceito de 'dispositivo'". Ao fazer uma revisão de suas pesquisas, Foucault menciona que seu trabalho estava voltado para uma história do pensamento, e que sua análise se daria sobre focos de experiência, nos quais "[...] se articulam uns sobre os outros: primeiro, as formas de um saber possível; segundo, as matrizes normativas de comportamentos para os 
indivíduos; e enfim os modos de existência virtuais para sujeitos possíveis" (FOUCAULT, 2010, p.5). Foi nessa perspectiva que o autor analisou, por exemplo, a experiência da loucura, entendendo experiência como a correlação entre "campos de saber, tipos de normatividade e formas de subjetividade" (FOUCAULT, 2012, p.10). É, portanto, a articulação desses três elementos que o autor denomina "foco de experiência", isto é, o ponto onde se fabrica, nesse caso, o louco: na conjunção do saber, da normatividade e da subjetivação sobre a vida. Para analisar o primeiro desses três elementos, qual seja, a formação dos saberes, Foucault procurou "identificar quais eram as práticas discursivas que podiam constituir matrizes de conhecimentos possíveis" (FOUCAULT, 2010, p.6) e, nessas práticas discursivas, buscou pelas regras que constituíam o jogo do verdadeiro e do falso (formas de veridicção). Já no que se refere à análise das matrizes normativas de comportamentos, o autor estudou as técnicas e procedimentos através dos quais se pretende conduzir a conduta dos outros e, nesse sentido, procurou colocar em discussão a questão da norma de comportamento e de como essa norma é investida de poder. Para o estudo da constituição do modo de ser do sujeito, o autor direcionou sua análise para as formas como o indivíduo é levado a se reconhecer como sujeito (de um discurso). São as formas de subjetivação e as técnicas que se estabelecem na relação do sujeito de si para consigo que se constituem no foco analítico do autor.

Embora no conjunto da obra desse autor seja possível localizar essas análises em livros ou em cursos que foram produzidos em momentos diferentes da sua trajetória de pesquisa, é possível estabelecer uma relação metodológica e analítica entre a constituição de saberes, os procedimentos ou técnicas de condução de condutas dos outros e as formas de subjetivação ou técnicas de condução da conduta de si mesmo. O próprio Foucault afirma isso na introdução do segundo volume da sua "História da Sexualidade" (FOUCAULT, 2012), ao tratar a experiência como "[...] o entrecruzamento dos mecanismos de saber e de poder que dão forma à experiência de si" (LÓPEZ, 2011, p.48). E é nesse sentido que a aproximação entre dispositivo e experiência se torna possível. Assim, teríamos focos de experiência, isto é, formas sujeitos, como produções de um dispositivo. O que nos possibilita pensar "[...] como a partir de estes 'dispositivos', foi possível uma determinada "experiência de si" e do outro" (LÓPEZ, 2011, p.49). E nisso se explicita a potencialidade metodológica e analítica do conceito de dispositivo, funcionando como uma ferramenta estratégica para a investigação no campo as Ciências Humanas e da Educação. 
Porém, cabe salientar que não consideramos coerente com a filosofia foucaultiana o uso direto, fazendo algo como uma aplicação, de qualquer um dos conceitos-ferramentas que nela encontremos. Tampouco se tem a ideia de que um conceito pode ser refinado progressivamente, tendo sua racionalidade ampliada crescentemente (FOUCAULT, 2009). Desse modo, apoiandonos em usos de outros autores (AGAMBEN, 2005; DELEUZE, 1990; MARCELLO, 2003; 2009; CAMINI, 2015) é que formulamos e defendemos a potencialidade da Numeramentalidade como dispositivo e ferramenta analítica e metodológica.

\section{Numeramentalidade como dispositivo histórico}

A Numeramentalidade pode ser pensada como um dispositivo histórico. Isso implica mostrar como se tornou possível, paulatinamente, a configuração de práticas numeramentalizadas ou numeramentalizadoras que obedecem a certas regras. Assim, neste momento, levantaremos argumentos para sustentar que o dispositivo da Numeramentalidade emerge como uma atualização (e uma possibilidade) dos modos de organização de saberes.

Em "As palavras e as Coisas", Foucault (2007) afirma que os atos comparativos pela medida e pela ordem, no século XVII, possibilitaram uma nova forma de conhecer, diferente da que se operava anteriormente. Amparando sua análise na obra de Descartes, o autor mostra o deslocamento da comparação como reveladora da ordem do mundo, para a comparação como uma operação de pensamento que vai do simples ao complexo. Medir e ordenar. Dois procedimentos que comporão a ordem discursiva do saber científico. Seria, então, o início do racionalismo: "podemos, se não tivermos na cabeça senão conceitos prontos, dizer que o século XVII marca o desaparecimento das velhas crenças supersticiosas ou mágicas e a entrada, enfim, da natureza na ordem científica" (FOUCAULT, 2007, p.75). A comparação passa a ser a prova que vai determinar, seja pela medida ou pela ordem, a certeza do conhecimento.

Um primeiro ponto fundamental destacado por Foucault na sua análise da épistémè clássica é a relação entre o saber e a máthêsis, "entendida como ciência universal da medida e da ordem" (FOUCAULT, 2007, p.78), que apresenta duas características principais: 1) a possibilidade de estabelecer entre as coisas, mensuráveis ou não, uma sucessão ordenada e 2) essa relação não deve ser entendida como uma imposição das matemáticas aos demais 
conhecimentos. O autor salienta que em grande parte dos domínios de conhecimento emergentes nesse período não há indícios de matematização. A relação, portanto, se dá no estabelecimento de uma ciência da ordem muito mais vinculada à estruturação de um sistema de signos do que de um sistema numérico. Tal relação se apresenta, segundo o autor, na gramática geral (ordem das palavras), na história natural (ordem dos seres) e na análise das riquezas (ordem das necessidades). Um segundo ponto que merece destaque é a afirmação de que ao se colocar o conhecimento em ordem através de signos, as empiricidades entram na ordem das identidades e das diferenças. De posse disso, considera-se que essa relação com a máthêsis reaparece na atualidade, porém, reatualizada naquilo que chamamos de dispositivo da Numeramentalidade, especialmente através dos saberes estatísticos e dos processos de classificação. Assim, poderíamos dizer que saímos de uma épistémè em que a máthêsis controlava a produção e a organização dos conhecimentos - em uma ordem discursiva -, chegamos a um dispositivo da Numeramentalidade no qual as ações de medir e de ordenar são reatualizadas e entram no jogo do poder-saber. Tal reatualização está associada ao disciplinamento dos saberes e a consequente incorporação dos mesmos naquilo que chamamos de ciência. Foucault (2010, p.153) afirma que "A ciência não existia antes do século XVIII" e que com o desaparecimento da máthêsis "como projeto de uma ciência universal que serviria tanto de instrumento formal quanto de funcionamento rigoroso a todas as ciências" (FOUCAULT, 2010, p.154), a ciência teria tomado o seu lugar, funcionando como disciplinadora dos saberes. Desse modo, as ações de medir e de ordenar entram no âmbito do fazer científico disciplinado, no qual se estabelece outro modo de relação entre saber e, agora, poder e, também, entre saber e verdade. Nesta última, vemos operar a produção da verdade pela produção do conhecimento científico.

Porém, as práticas classificatórias e os saberes numéricos, reatualizados no dispositivo da Numeramentalidade, não se restringem ao domínio científico. Se tínhamos uma épistémè organizada pela máthêsis, medindo e ordenando as práticas em uma ordem discursiva, teremos, posteriormente, um dispositivo da Numeramentalidade, que organiza práticas quantificadoras e classificatórias, em uma ordem que não é mais apenas discursiva, é também não discursiva, e abrange não apenas o saber, mas também o poder e a subjetivação. É nesse sentido que somos levados a pensar na emergência do dispositivo da Numeramentalidade como uma racionalidade 
na qual os domínios de saber não funcionam apenas em um âmbito descritivo-discursivo, mas também em um âmbito estratégico, como forjadores de formas de ser e agir.

Como apontou Foucault, com a invenção das ciências do homem, e dos sujeitos desses discursos (sujeito que fala, sujeito que produz, sujeito que vive), inventam-se mecanismos disciplinares de modo a normalizar e otimizar a conduta de cada um. Essas ações tinham como foco o homem-corpo, individualmente, engendrando estratégias, técnicas, exercícios para dele tirar as suas máximas forças:

[...] nos séculos XVII e XVIII, viram-se aparecer técnicas de poder que eram essencialmente centradas no corpo, no corpo individual. Eram todos aqueles procedimentos pelos quais se assegurava a distribuição espacial dos corpos individuais (sua separação, seu alinhamento, sua colocação em série e em vigilância) e a organização, em torno desses corpos individuais, de todo um campo de visibilidade (FOUCAULT, 2010, p.203).

Com a governamentalização do estado moderno (FOUCAULT, 2008), contudo, outra forma de poder passa a atuar, integrando-se ao poder disciplinar. Esse homem-corpo passa a ser visto compondo uma espécie, "[...] uma massa global, afetada por processos de conjunto que são próprios da vida [...]" (FOUCAULT, 2010, p.204). Sobre o homem-espécie passa a atuar o biopoder. O foco dessa forma de poder é uma população cujos fenômenos e regularidades também precisam ser controlados e normalizados.

A temática do governo ou governamento, apesar de não ser o foco central, percorre uma parte significativa da obra de Foucault. Ainda que a preocupação central das investigações de Foucault tenha sido, conforme ele mesmo afirmou em alguns momentos, a constituição do sujeito na sua relação com a verdade - ou como nos tornamos o que somos -, o autor percebeu que a maneira pela qual essa constituição é possível se faz, em grande parte, pelo governamento das condutas, tanto no âmbito individual quanto no coletivo. E é justamente "o encontro entre as maneiras pelas quais os indivíduos são dirigidos por outros e os modos como conduzem a si mesmo" (FOUCAULT, 2011b, p.155) que o autor irá chamar de "governo". Essa compreensão acerca do governo como condução de condutas, especialmente a partir da década de 1980, visibiliza um deslocamento operado pelo autor da noção de poder-saber para a noção de governo pela verdade. Esse deslocamento provoca uma ampliação em seu pensamento e 
“conecta o interesse em uma 'política anatômica do corpo humano' com a investigação dos processos de subjetivação e as formas morais ou políticas de existência" (LEMKE, 2014, p.110).

O dispositivo da Numeramentalidade, com seus procedimentos de medida, de quantificação, de classificação, integra essas duas dimensões de governo dos homens - o governo do corpo e o governo da população. É nesse quadro que Foucault (2008) estabelece a emergência da estatística como um saber do Estado que, nessa transição - nesse processo de governamentalização do Estado que instaura uma nova matriz de racionalidade - produz informações necessárias à nova forma de governo que está se estabelecendo.

A população é esse novo corpo que será alvo do biopoder e de suas técnicas específicas de controle, regulação, monitoramento e normalização. As estatísticas serão convenientes ao governo da população, pois através delas dá-se a conhecer os "[...] elementos que permitem a manutenção e o desenvolvimento das forças" (BELLO; TRAVERSINI, 2011, p.859). As estatísticas se mostram capazes de articular um poder disciplinar, individualizante, com um poder biopolítico, massificante. Pois elas, ao mesmo tempo em que organizam um espaço de visibilidade a partir da distribuição (classificação) daquilo que foi quantificado ou medido, também colocam em operação, a partir dessas quantificações, mecanismos de previsões, de estimativas, com foco de intervenção em nível global. Ou seja, parte-se de um mapeamento no nível individual - do corpo-homem - para uma intervenção no nível da população - ao homemespécie. Segundo Desrosières (2004), na década de 1830, passa a ser difundido o argumento que enlaça o discurso probabilístico com as observações estatísticas. $\mathrm{O}$ autor argumenta que

esta construção mantém unidos, por um lado, o aspecto aleatório e imprevisível dos comportamentos individuais e, por outro, a regularidade e, por conseguinte, a previsibilidade do cálculo estatístico desses atos individuais através da noção de homem médio. Se apoia na generalidade da distribuição gaussiana de probabilidade (a futura 'lei normal') e também nas séries da 'estatística moral' (matrimônios, crimes, suicídios) elaboradas pelas oficinas estatísticas (DESROSIÈRES, 2004, p.24, tradução nossa).

Conforme apontado na citação, a noção de homem médio congregaria esse caráter individualizante e totalizador possibilitado pela estatística.

É interessante considerar que Foucault localiza a emergência dessa preocupação com a

Periódico Horizontes - USF - Itatiba, SP - Brasil - e019025 
população com sua correlata forma de poder - o biopoder - na segunda metade do século XVIII, mesmo século em que localizou a emergência da ciência como forma de organização do saber, em detrimento da máthêsis. Podemos considerar que esses fatores seriam pontos de proveniência para a emergência do dispositivo da Numeramentalidade, reatualizando tanto as formas de medir e ordenar no âmbito científico e de produção da verdade, quanto na utilização desses conhecimentos no âmbito da gestão do Estado, investindo-os de poder, contribuindo para o processo de governamentalização do Estado.

Nesse sentido, o dispositivo da Numeramentalidade apresenta os seus primeiros traços como uma reatualização das práticas de medir, de quantificar, de classificar - anteriormente organizadas pela máthêsis - com vistas a responder a essa nova racionalidade, na qual se "[...] outorga valor de verdade aos números, permitindo o governamento das instituições sociais e a modelação das condutas, com impactos na tomada de decisão de caráter político" (LOPEZ BELLO; RÉGNIER, 2017, p.119). É por esse caráter normativo dos números e das estatísticas produzidas no dispositivo da Numeramentalidade que se extrapola o domínio científico e da disciplina, pois há ações de governamento atreladas a esses números, que além de organizar formas de ver o "real", operam na orientação e na condução de condutas.

\section{O dispositivo da Numeramentalidade: uma grade analítica}

Tendo em vista o que foi apresentado anteriormente, toma-se o dispositivo da Numeramentalidade, também, como uma grade de inteligibilidade, como um aparelho, com o objetivo de focar um problema histórico específico (DREYFUS; RABINOW, 2013). Bello (2012a) destaca que a Numeramentalidade pode ser vista não apenas como um dispositivo, mas também como uma ferramenta metodológica e conceitual para se entender a produção de tecnologias de governamento das instituições e das práticas de gestão (das escolas, dos currículos, das práticas pedagógicas etc.) com impactos na tomada de decisão de caráter político. A ideia de tecnologia agrega à ideia de prática as noções de estratégia e tática: "com efeito, estudar as práticas como técnicas ou tecnologias consiste em situá-las em um campo que se define pela relação entre meio (táticas) e fins (estratégias)" (CASTRO, 2009, p.412). Além disso, a ideia foucaultiana de tecnologia congrega a dimensão do poder voltado para os outros, (podendo ser 
nomeada de tecnologia de governamento), e a dimensão do poder voltado para si mesmo, ao tratar das tecnologias de si ou de subjetivação, direcionadas para a maneira de regular a conduta de si mesmo. As tecnologias de governamento, portanto, necessitam de um discurso verdadeiro, de táticas e de finalidades.

Tomar a Numeramentalidade como o dispositivo que amarra tecnologias de governamento, táticas, jogos de verdade e estratégias - constituindo uma grade analítica mostra-se produtivo, pois se pode compreender como, em certo período histórico, "se operam práticas, constituem-se discursos e identidades, regulam-se condutas, incitando-se, sempre que possível, a processos de subjetivação" (BELLO, 2012b, p.22). A compreensão do conceito de dispositivo formulada por Agamben (2005, p.13) vem ao encontro do que temos tentado argumentar a respeito da Numeramentalidade: “[...] chamarei literalmente de dispositivo qualquer coisa que tenha de algum modo a capacidade de capturar, orientar, determinar, interceptar, modelar, controlar e assegurar os gestos, as condutas, as opiniões e os discursos dos seres viventes" (AGAMBEN, 2005, p.13).

Os aspectos do programa de pesquisa proposto por Bello (2012a) servem de inspiração para a realização de pesquisas que se interessem pelos saberes numéricos produzidos contemporaneamente, pois a abrangência do Dispositivo da Numeramentalidade engloba as diversas práticas envolvendo a produção numérica, seus usos e seus significados. Dentre os números produzidos pela nossa sociedade, na atualidade, as estatísticas têm se tornado foco de análise em pesquisas que buscam compreender seus efeitos e sua produção. Foucault afirma que a família é um dos "elementos táticos mais preciosos" para o funcionamento do dispositivo de sexualidade (FOUCAULT, 2011c, p.122). Em analogia, consideramos que as estatísticas são elementos táticos preciosos para o funcionamento do dispositivo da Numeramentalidade, especialmente quando pensamos nesse dispositivo no âmbito da Educação, como é o caso da maioria das pesquisas em que esta ferramenta analítica se tornou produtiva.

\section{O dispositivo da Numeramentalidade: um programa de pesquisa}

Como já enunciamos anteriormente, o conceito de Numeramentalidade foi criado por analogia ao conceito foucaultiano de Governamentalidade e é entendido "como a combinação

$$
\text { Periódico Horizontes - USF - Itatiba, SP - Brasil - e019025 }
$$


entre essas artes de governar e as práticas e as normatividades em torno do numerar, do medir, do contabilizar, do seriar, as quais orientam a produção enunciativa das práticas [...]" (BELLO; 2012a, p.104). Tal conceito propõe uma perspectiva analítica para o estudo

[...] dos processos de governo e ao [do] caráter normativo das linguagens e dos saberes constituintes de tais processos, normatividades essas produtoras, orientadoras e reguladoras de condutas, modos de pensar e agir; normatividades que na contemporaneidade se baseiam fortemente na quantificação, na medição, no uso e registro de números (BELLO; 2012a, p.104).

A analogia entre Numeramentalidade e governamentalidade estabelecida por Bello (2012a, 2012b) remete diretamente à relação entre saber e poder, já que governamentalidade funciona como uma grade de análise a partir da qual se pode analisar as "relações de poder, ou seja, para analisar a maneira como se conduz a conduta dos homens" (TRAVERSINI; BELLO, 2009, p.142). Foucault argumenta que as relações de poder podem ser entendidas como estratégias para se governar, para se conduzir a conduta dos outros. E, por esse ângulo, podemos compreender como jogos de verdade se acham imbricados nas relações de poder, pois o discurso verdadeiro está na raiz da governamentalidade (FOUCAULT, 2010). Esse entendimento favorece uma compreensão acerca do funcionamento e do direcionamento de comportamentos na relação com os outros e consigo mesmo.

Nesse sentido, a Numeramentalidade pode ser entendida como um dispositivo do nosso tempo, que, através das suas curvas de visibilidade e regimes de enunciabilidade, organiza práticas numeramentalizadas, que produzem formas de ver e de dizer, orientam e incitam modos de pensar e de agir que, por sua vez, criam maneiras de ser na contemporaneidade.

Sobre a potencialidade analítica da Numeramentalidade e seus desdobramentos como programa de pesquisa, conforme referido em Bello (2012a), quatro linhas de ação são traçadas:

1. uma analítica histórico-filosófica a ser empreendida no intuito de se explicar como a nossa sociedade foi aos poucos se numeramentalizando, isto é, como foram se desvinculando os domínios de saber - neste caso, aqueles referentes ao uso das quantidades, dos números, das medidas, das séries - engendrados a partir de práticas sociais, constituindo-se como conjuntos autônomos e heterogêneos de normas, estratégias e ações; ou seja, as disciplinas.

2. uma problematização em torno da produção discursiva, do ponto de vista

Periódico Horizontes - USF - Itatiba, SP - Brasil - e019025 
cognitivo (as numeralizações) e sócio-culturais (os numeramentos), na linha do poder-saber, que têm fabricado sujeitos, identidades culturais, hierarquizado diferenças, com base nos usos, expressões e manejos dessas quantidades, registros, medidas, operações por parte dos indivíduos e de suas instituições.

3. Uma grade de análise para se entender a produtividade da centralidade das quantidades, dos números (medições, índices, taxas), seus registros e usos e que, na racionalidade política governamental neoliberal contemporânea, vem provocando, conduzindo, dirigindo, orientando modos de pensar e de agir dos indivíduos na sociedade;

4. O entendimento de produção de toda uma tecnologia de governamento, no sentido Foucaultiano, de incidência institucional e de gestão (escolas, currículos, campanhas educacionais) para a tomada de decisão e intervenção política com base nos números e seus usos como expressão da verdade (BELLO, 2012a, p.104-105).

Dentro desse programa de pesquisa, a Numeramentalidade já foi utilizada para ensaiar análises no campo da Educação e da Saúde. Um primeiro trabalho trata da inserção dos saberes estatísticos nas práticas curriculares contemporâneas. Bello e Traversini (2011) problematizam a curricularização do saber estatístico nos diferentes níveis de ensino, argumentando que esse saber, quando adquirido na escola, disciplina o olhar do indivíduo sobre o seu cotidiano, fazendo com que o aluno explique e a aja sobre o mundo de uma determinada maneira. Além disso, os autores também argumentam que a inserção dos saberes estatísticos nas práticas curriculares responderia à necessidade de administração do risco do social, produzindo sujeitos prudentes.

Em Bello e Sperrhake (2016) desenvolve-se uma análise na qual se apontou para curricularização do saber estatístico estando de acordo "[...] com demandas e práticas da ordem governamental, revestidas de uma importância epistemológica" (p.423). Analisa-se, também, que a "[...] psicologia do desenvolvimento cognitivo funciona como uma racionalidade, como um modo de pensar o sujeito-aluno infantil para o qual as práticas escolares vinculadas ao ensino do saber estatístico estão moldadas" (p.423). Assim, primeiramente, é necessário familiarizar o aluno com a "gramática estatística", para, posteriormente, avançar tanto para a utilização de ferramentas matemáticas mais avançadas quanto para incluir a curricularização do risco e de seu gerenciamento.

Já Bello, Régnier e Sperrhake (2014) analisam como “[...] a normatividade numérica está implicada na produção e modificação de condutas desde um aspecto mais amplo, como a formulação de políticas públicas, até em um aspecto mais micro, como a ação pedagógica de 
professores em sala de aula" (p.1). Nesse sentido, mostra-se como o Pacto Nacional Pela Alfabetização na Idade Certa (PNAIC), através de dados produzidos por uma avaliação em larga escala, investe na conduta de professoras alfabetizadoras com vistas a alfabetizar as crianças.

O conceito de Numeramentalidade tem auxiliado também a pensar como e por que o IDEB governa a instituição escolar (BELLO, 2012b), uma vez que essa ferramenta analítica permite discutir

[...] o caráter normativo dos saberes em torno dos índices de desempenho para se governar e se conduzir as condutas dos sujeitos escolares, como uma questão de verdade que orienta modos de pensar e agir pelas práticas curriculares que institui e as posições identitárias que produz (BELLO, 2012b, p.26).

Assim, o autor mostra como o índice mobiliza condutas e procedimentos com o objetivo de melhorar o desempenho e a eficiência da Educação escolar.

Kreutz (2012) também faz uso da ferramenta da Numeramentalidade para analisar os números produzidos na área da saúde como uma forma de legitimar o saber dessa área e instituir práticas de governo das populações. O autor analisa a produção de registros numéricos dos Agentes Comunitários de Saúde e de como esses registros integram mecanismos que regulam e projetam a formação desse profissional, bem como das comunidades que são alvo do programa.

Já Pinho (2013) mobiliza o conceito para analisar as práticas escolares que fazem uso dos números e seus registros. A autora mostra como as práticas escolares, numa problematização indisciplinar da matemática, constituem-se como jogos nos quais numerar, ordenar e ler operam estrategicamente nas formas de se conduzir a conduta dos indivíduos.

Sperrhake (2016) utiliza do conceito de Numeramentalidade para analisar documentos relacionados à Avaliação Nacional da Alfabetização (ANA) visando traçar as linhas desse dispositivo que operam na constituição das práticas avaliativas em larga escala. Ao colocar em funcionamento esse conceito, entendido como um dispositivo de nossa época, a autora traçou três tramas discursivas entre as suas linhas. A primeira trama aborda a produção do risco do analfabetismo infantil e as estratégias de produção numérica das práticas avaliativas para comparar. A segunda trama trata da metodologia adotada nos testes de desempenho da ANA, marcada pela medição e por processos classificatórios, a partir dos quais se discute a construção 
de níveis de leitura e escrita proposta pelas escalas de proficiência da ANA. Na terceira trama argumenta-se que o dispositivo da Numeramentalidade produz formas-sujeito e subjetividades numeramentalizadas.

Tomando o dispositivo da Numeramentalidade como um programa de pesquisa, cabe destacar que a matemática é vista como um jogo, que assim como a linguagem corrente nos permite "[...] pensar em um conjunto amplo e variado de signos que, articulados por regras de significação, constituem formas de pensar objetos empíricos; formas de atribuirmos significados às palavras quando operamos com elas em uso, segundo determinadas atividades" (BELLO, 2012a, p.90).

Nesse sentido, a noção de jogo impele a pensarmos na noção de regras, e é assim que chegamos a uma perspectiva de linguagem de caráter normativa. As matemáticas e suas proposições podem, assim, ser tomadas como "[...] normas constitutivas das práticas a partir das quais, sem dúvidas, organizamos nossa experiência empírica" (BELLO, 2012a, p.91). O autor complementa argumentando que a matemática não funcionaria descrevendo uma situação observável, desvelada, descoberta, a ser ou não interpretada, mas que ela faria parte da própria constituição da situação, produzindo-a. Essa concepção normativa da matemática permite que a vejamos não apenas como um campo de saber, numa perspectiva epistemológica, mas também, e principalmente, como um conjunto de regras que constituem práticas que operam no dispositivo da Numeramentalidade, incitando e produzindo condutas, comportamentos e subjetividades. Além disso, "[...] o que denominamos de matemática trata-se de uma maneira muito particular de entender o tempo e o espaço, de classificar e ordenar o mundo, e de compreender as relações sociais e políticas" (LOPEZ BELLO; RÉGNIER, 2017, p.116). Dessa forma, podemos problematizar o estatuto científico atribuído à matemática, ao mesmo tempo em que entendemos o quanto esse saber pode atuar, e atua, como um "dizer verdadeiro" (FOUCAULT, 2010), investido de poder.

Bello (2012a) considera, ainda, a possibilidade de tratar a Numeramentalidade em meio a processos de Numeramentalização, ampliando a possibilidade analítica do conceito ao considerar a produção de singularidades numa perspectiva do governo de si sobre si mesmo atrelado a uma formação ética.

Periódico Horizontes - USF - Itatiba, SP - Brasil - e019025 
Numeramentalidade: suas linhas de subjetivação - o "efeito amarra"

Pensar o sujeito não como autêntico ou com uma interioridade [...] mas como a linha de chegada de uma tensão constituinte que utiliza uma força e, como na metáfora estoica, olha para o EU como um alvo de um arqueiro, e não como uma base (CHIGNOLA, 2014, p.10).

A citação escolhida para abrir esta última seção nos permite considerar as linhas de subjetivação de um dispositivo muito mais como efeitos da relação entre as linhas de saberpoder. Elas (as linhas de subjetivação) são o alvo, não o ponto de partida.

É preciso considerar, desde logo, que se trata aqui dos processos de subjetivação produzidos pelas relações entre subjetividade e verdade estabelecidas no escopo do dispositivo da Numeramentalidade. Nesse sentido, o que se analisará serão as posições de sujeito, ou as "funções sujeito" (DELEUZE, 2005, p.54) que se produzem pela articulação de saberes com vistas a conduzir as condutas dos indivíduos de algumas maneiras possíveis. Assim, o que se estará tratando por ora, não é da produção de um si mesmo como obra de arte; mas sim procuramos elucidar as subjetividades ali produzidas e de que maneira uma trama discursiva se forma de modo a convocar os indivíduos a se sujeitarem a essas subjetividades, tornando possível a ocupação (ou não) daqueles lugares ou posições discursivas.

Lazzarato (2014) aponta que a problemática da subjetivação está em pauta entre os pensadores críticos - especialmente os franceses - desde os anos 1960. O autor elenca, baseado em Felix Guattari, alguns obstáculos a serem enfrentados ao se tratar deste tema. O primeiro deles se refere ao "impasse estruturalista" (LAZZARATO, 2014, p.54), a partir do qual a constituição da subjetividade seria resultado de processos linguísticos significantes. O segundo obstáculo está vinculado à fenomenologia e à psicanálise, a partir das quais a subjetividade seria engendrada por pulsões, afetos, memórias e sensibilidades - "instâncias intrassubjetivas e relações intersubjetivas" (LAZZARATO, 2014, p.54). O terceiro obstáculo apontado pelo autor é o sociológico, que apontaria para a constituição da subjetividade por processos coletivos, que vão além dos individuais. E, por fim, o último enfrentamento

[...] que Guattari chama de 'complexo das infraestruturas': uma infraestrutura Periódico Horizontes - USF - Itatiba, SP - Brasil - e019025 
material que gera uma superestrutura ideológica (marxismo), uma infraestrutura instintiva que gera a psique (Freud), ou mesmo estruturas sintáticas e linguísticas profundas que produzem conteúdo linguístico (significados) (LAZZARATO, 2014, p.54).

A concepção de subjetividade que se toma aqui está vinculada ao a priori histórico, isto é, aquela que considera que

A existência vem antes da essência; somos constituídos por aquilo que fazemos. Mas nossas escolhas livres só podem ser feitas entre as ações que nos estão disponíveis, as ações possíveis. E nossos modos de ser, escolhidos livremente ou não, encontram-se entre modos possíveis de ser (HACKING, 2009, p.35).

Desse modo, mesmo com as linhas de saber-poder do dispositivo da Numeramentalidade ancoradas no fazer científico numérico, temos elementos para pensar a produção de modos de ser sujeito.

As linhas de subjetivação convocam continuamente os indivíduos a estabelecerem relações de força consigo mesmo. E, ainda, “[...] como este indivíduo aprende a apreender, para a constituição de si, um jogo de regras, uma gramática, a qual é produzida e colocada em circulação [...]" (MARCELLO, 2003, p.95) na contemporaneidade pela via, dentre outras práticas, do dispositivo da Numeramentalidade. Porém, não há nessa compreensão um aprisionamento do sujeito nas tramas do dispositivo, pois "Estamos sempre amarrados a dispositivos, mas dentro deles agimos [...]” (CHIGNOLA, 2014, p.10). Há, portanto, uma dupla posição: “[...] somos nós quem constituímos a nós mesmos como sujeitos e súditos por meio dos mecanismos de poder dos quais participamos" (HACKING, 2009, p.16, grifo nosso).

Deslocando a questão do poder para o governo de si e dos outros, tal como sugere Foucault, somos levados a considerar que os processos de subjetivação estabelecem formas dos indivíduos se relacionarem às verdades de seu tempo, incitando maneiras de se conduzir e de ser, convocando esses indivíduos a, livremente, sujeitarem-se a essas verdades: “[...] é no momento em que somos chamados a nos constituir como Sujeito que aceitamos o império dos discursos científicos e não científicos que têm por função revelar aquilo o que verdadeiramente somos" (AVELINO, 2011, p.35). Ou seja, o jogo de verdade próprio da prática científica comporta modos específicos de vincular a verdade, que ela própria produz, ao sujeito (FOUCAULT, 2011b). 
A noção de "invenção de pessoas", do filósofo da ciência lan Hacking (2009), discute de que modo "as classificações de pessoas afetam as pessoas classificadas, como mudamos em virtude de sermos classificados, e como as maneiras como mudamos têm uma espécie de efeito feedback sobre nossos próprios sistemas de classificação" (p.115). Pensar sobre como as classificações contemporâneas criam e definem objetos de conhecimento e a própria verdade da ciência nos coloca frente à questão, abordada por Foucault (2007), da maneira "como as palavras impõem uma ordem às coisas" (HACKING, 2009, p.49); e como essa ordem das coisas ordena também o nosso pensamento. Nesse sentido, podemos questionar a produção da verdade científica utilizando o argumento de Hacking de que, na invenção de categorias para os fenômenos sociais "podemos gerar tipos de pessoas e tipos de ações na medida em que imaginamos novas classificações e novas categorias" (HACKING, 2009, p.55). E, além disso, a própria forma de produção de certas classificações, no fazer científico, convoca os indivíduos a tomarem-nas como verdade e, como diz Foucault, "se é verdade, portanto, eu me inclino" (FOUCAULT, 2011b, p.81); eu me curvo a essa verdade e a partir dela, sobre ela, de posse dela, conduzo minhas ações de uma forma que não "existia" antes da referida nova classificação.

Para exemplificar esse ponto, Hacking (2009) toma a produção das estatísticas do século XIX estudadas por ele, argumentando que até que houvesse certa prática de contagem de certos tipos de pessoa, esses mesmos tipos de pessoas não existiam, pois as contagens "faziam parte da criação elaborada, bem intencionada, na verdade inocente, de novos tipos de modos para as pessoas serem, e as pessoas inocentemente 'escolhiam' encaixar-se nessas novas categorias" (p.64).

Todas essas análises feitas por Hacking apontam que as classificações e as contagens (estatísticas) - produzidas pelo fazer científico e que no dispositivo da Numeramentalidade configuram as linhas de saber-poder - atuam na relação que o indivíduo estabelece consigo mesmo para se pensar e se conduzir. Consideramos aqui que a relação entre governo pela verdade e pelos processos de subjetivação, no âmbito do dispositivo da Numeramentalidade, faz uso das estatísticas e da prática da classificação, investidas de força para conduzir condutas e vincular indivíduos a essas verdades. Pois as linhas de saber-poder desse dispositivo estão fortemente pautadas na ciência, e esta é

Periódico Horizontes - USF - Itatiba, SP - Brasil - e019025 
[...] uma família de jogos de verdade que obedece todos ao mesmo regime no qual o poder da verdade foi organizado de maneira que a constrição seja assegurada pelo próprio verdadeiro. É um regime no qual a verdade constrange e liga porque e na medida em que é verdadeiro (FOUCAULT, 2011b, p.84).

Desse modo o que estabelece o processo de vinculação dos indivíduos às verdades do dispositivo da Numeramentalidade é, em parte, o caráter científico das proposições por ele postas em circulação. O processo de subjetivação estaria, de certo modo, garantido pela autoindexação do verdadeiro próprio dos discursos científicos da estatística e de procedimentos de classificação. Porém, é claro, como mencionado anteriormente, o dispositivo não é fechado; ele possui espaços abertos, ainda não preenchidos; é cruzado por linhas de outros dispositivos; e é composto por linhas que, talvez, não sejam tão possíveis assim de serem mapeadas, descritas e analisadas. E também, apesar de ser um efeito das relações poder-saber, o indivíduo não é passivo. Considerando, na esteira do pensamento de Foucault, que "[...] as relações de poder suscitam necessariamente, apelam a cada instante, abrem a possibilidade a uma resistência [...]" (FOUCAULT, 2015a, p.227), não seria possível analisar o dispositivo da Numeramentalidade sem atentar para as formas de resistência nele produzidas. Uma vez que, apesar da afirmação de que não se pode estar "fora" do poder, isso "[...] não quer dizer que se está inteiramente capturado na armadilha" (FOUCAULT, 2015b, p.243). Na concepção foucaultiana de poder, estão implicadas também as ações de resistência que não são o outro do poder, mas inversões, torções nos vetores de força.

Assim, resistir às forças engendradas em um dispositivo possibilita que se espace das linhas de saber-poder e, portanto, se escape também dos processos de subjetivação constituidores de identidades. Esse escape produz algo que ainda não está codificado; algo que não se fez linguagem no interior do dispositivo; algo que foge aos domínios das linhas já delimitadas e definidas. Esse escape produz singularidades. Por esse motivo preferimos tratar da resistência e da fuga como pontos, e não como linhas, do dispositivo, pois ao passo que esse movimento possa ser feito linguagem e, dessa forma, possa ser compreendido, classificado, posicionado, deixa de ser fuga e resistência, e novamente entra no escopo das linhas de visibilidade e dizibilidade.

Periódico Horizontes - USF - Itatiba, SP - Brasil - e019025 


\section{Considerações Finais}

Foi com o propósito de mostrar e argumentar que o dispositivo da Numeramentalidade nos auxilia na formulação de entendimentos sobre as práticas numéricas atuais que este artigo foi produzido. Foucault explicita sua vontade ao estudar a sexualidade da seguinte forma: "Gostaria de passar em revista não somente esses discursos, mas ainda a vontade que os conduz e a intenção estratégica que os sustenta" (FOUCAULT, 2011c, p.15). A partir disso e no âmbito do dispositivo da Numeramentalidade, somos levados a problematizar porque os números, em suas diversas formas e modos de expressão e registro, são percebidos tão inequivocamente, com tanta certeza e solidez em nossa sociedade; porque, mesmo quando são questionados, não é possível deles livrar-se; como e porque esses signos e seus processos são tão valorizados pela sua veracidade, enquanto outros signos (linguísticos, imagéticos) não o são. A que vontade de poder, a que intenção estratégica, responde a centralidade dos números na contemporaneidade? São esses questionamentos que nos conduzem nas investigações que temos construído tendo como ferramenta conceitual, metodológica e analítica a Numeramentalidade, tomando-a como um dispositivo de nossa época.

Cabe, por fim, considerar que uma analítica que faz uso do dispositivo da Numeramentalidade não se limita às possibilidades de análises aqui apresentadas. A ideia de utilizar esse dispositivo extrapola o que aqui se apresenta. Com isso, queremos salientar a potencialidade do conceito para a análise de outras práticas envolvendo números, quantificações, medidas, classificações, entre outras. E, mais ainda, convém demarcar a necessidade de estudos que focalizem o que chamamos de "efeito amarra" do dispositivo, ou seja, estudos que focalizem os processos de subjetivação decorrentes dos saberes e das normatividades numéricas.

\section{Referências}

AGAMBEN, G. O que é um dispositivo? Trad. Nilcéia Valdati. Outra Travessia, Florianópolis, n.5, p.9-16, 2005.

AVELINO, N. Foucault e a anarqueologia dos saberes. In: FOUCAULT, M. Do governo dos vivos. 
Trad. Nildo Avelino. São Paulo: Centro de Cultura Social; Rio de Janeiro: Achiamé, 2011, p.1737.

BELLO, S. E. L. Numeramentalização: o estudo das práticas e do governamento em educação (e) matemática na contemporaneidade. Reflexão e Ação, Santa Cruz do Sul, v. 20, n. 2, p.88-114, $\mathrm{jul} / \mathrm{dez}$. 2012a.

BELLO, S. E. L. As práticas curriculares em Matemática que se produzem pelo governo do IDEB. Horizontes. Bragança Paulista, v.30, n.2, p.19-30, jul./dez. 2012b.

BELLO, S. E. L.; TRAVERSINI, C. S. Saber estatístico e sua curricularização para o governamento de todos e de cada um. Bolema, Rio Claro, v.24, n.40, p.855-871, 2011.

BELLO, S. E. L.; RÉGNIER, J C.; SPERRHAKE, R. Quando os números produzem formas-sujeito: a quantificação como prática de governo. In: ENCONTRO DE ETNOMATEMÁTICA DO RIO DE JANEIRO, 2014, Niterói. Anais... Niterói, 2014, p.199-213.

BELLO, S. E. L.; SPERRHAKE, R. Educação e risco social na curricularização do saber estatístico no Brasil. Acta Scientiarum Education, Maringá, v.38, n.4, p.415-424, oct.-dec., 2016.

CALDEIRA, M. C. S. Dispositivos da infantilidade e da antecipação da alfabetização no currículo do 1 o ano do ensino fundamental: conflitos, encontros, acordos e disputas na formação das crianças de seis anos. 2016. 263f. Tese (Doutorado em Educação) - Programa de Pós-Graduação em Conhecimento e Inclusão Social da Faculdade de Educação, Universidade Federal de Minas Gerais, Belo Horizonte, 2016.

CAMINI, P.Por uma problematização da classificação das escritas infantis em níveis psicogenéticos. 2015. 155f. Tese (Doutorado em Educação) - Programa de Pós-Graduação em Educação da Faculdade de Educação, Universidade Federal do Rio Grande do Sul, Porto Alegre, 2015.

CASTRO, E. Vocabulário de Foucault: um percurso pelos seus temas, conceitos e autores. Trad. Ingrid M. Xavier. Belo Horizonte: Autêntica, 2009.

CHIGNOLA, S. Sobre o dispositivo: Foucault, Agamben, Deleuze. Trad. Sandra Dall Onder. Cadernos IHU Ideias, São Leopoldo, v.12, n.214, p.4-18, 2014.

CORAZZA, S. M. História da infância sem fim. 2.ed. ljuí: Ed. Unijuí, 2004.

DALLA ZEN, L. H. O dispositivo pedagógico da arte. 2011. 108f. Dissertação (Mestrado em Educação) - Programa de Pós-Graduação em Educação da Faculdade de Educação, Universidade Federal do Rio Grande do Sul, Porto Alegre, 2011.

DELEUZE, G. O que é o dispositivo? In: Michel Foucault, filósofo. Barcelona: Gedisa, 1990, p.155-161. 
DELEUZE, G. Foucault. Trad. Claudia S. Martins. São Paulo: Brasiliense, 2005.

DESROSIÈRES, A. La política de los grandes números. 1. ed. Trad. Mónica S. Nasi. Editorial Melusina, 2004.

DREYFUS, H. L.; RABINOW, P.Michel Foucault: uma trajetória filosófica: para além do estruturalismo e da hermenêutica. 2. ed. Trad. Vera Portocarrero, Gilda G. Carneiro. Rio de Janeiro: Forense Universitária, 2013.

FISCHER, R. M. B. O dispositivo pedagógico da mídia: modos de educar na (e pela) TV. Educação e Pesquisa, São Paulo, v.28, n.1, p.151-162, jan./jun., 2002. Disponível em: http://www.scielo.br/pdf/ep/v28n1/11662.pdf. Acesso em 13 ago. 2016.

FOUCAULT, M. As palavras e as coisas: uma arqueologia das ciências humanas. 9. ed. Trad. Salma T. Muchail. São Paulo: Martins Fontes, 2007.

FOUCAULT, M. Segurança, território, população: curso no Collège de France (1977-1978). Trad. Eduardo Brandão. São Paulo: Martins Fontes, 2008.

FOUCAULT, M. A arqueologia do saber. 7. ed. Trad. Luiz Felipe B. Neves. Rio de Janeiro: Forense Universitária, 2009.

FOUCAULT, M. O governo de si e dos outros: curso no Collège de France (1982-1983). Trad. Eduardo Brandão. São Paulo: Editora WMF Martins Fontes, 2010.

FOUCAULT, M. Sobre a história da sexualidade. In: MACHADO, R. Microfísica do poder. 29. reimp.Trad. Roberto Machado. Rio de Janeiro: Graal, 2011a, p.242-276.

FOUCAULT, M. Do governo dos vivos: curso no Collège de France (1979-1980) - aulas de 09 a 30 de janeiro de 1980. Trad. Nildo Avelino. São Paulo: Centro de Cultura Social, 2011b.

FOUCAULT, M. História da sexualidade 1: a vontade de saber. 21. reimp.Trad. Maria Thereza C. Albuquerque e J. A. Guilhon Albuquerque. Rio de Janeiro: Edições Graal, 2011c.

FOUCAULT, M. História da sexualidade 2: o uso dos prazeres. 13. ed. Trad. Maria Thereza C. Albuquerque. Rio de Janeiro: Edições Graal, 2012.

FOUCAULT, M. Poder e saber. In: MOTTA, M. B. Ditos e Escritos, volume IV: estratégia, podersaber. 3. ed. Trad. Vera Lucia A. Ribeiro. Rio de Janeiro: Forense Universitária, 2015a, p.218235.

FOUCAULT, M. Poderes e estratégias. In: MOTTA, M. B. Ditos e Escritos, volume IV: estratégia, poder-saber. 3. ed. Trad. Vera Lucia A. Ribeiro. Rio de Janeiro: Forense Universitária, 2015b, p.236-246. 
HACKING, I. Ontologia histórica. Trad. Leila Mendes. São Leopoldo: Editora Unisinos, 2009.

JELINEK, K. R.; BELLO, S. E. L; SANTOS, S. A. Educação matemática: linguagens, práticas e sujeitos. Porto Alegre: Canto-Cultura e Arte, 2017.

KREUTZ. J. A. Quem conta um ponto, inventa um conto: fabricação de identidades em processos de numeramentalização da Saúde coletiva. 2012. 127f. Dissertação (Mestrado em Educação) Programa de Pós-Graduação em Educação da Faculdade de Educação, Universidade Federal do Rio Grande do Sul, Porto Alegre, 2012.

LAZZARATO, M. Signos, máquinas, subjetividades. Trad. Paulo D. Oneto e Hortência Lencastre. 1.ed. São Paulo: Edições Sesc São Paulo, 2014.

LEMKE, T. Os riscos da segurança: liberalismo, biopolítica e medo. In: AVELINO, N.; VACCARO, S. Governamentalidade, segurança. São Paulo/ Brasília: Intermeios/CAPES, 2014, p.105-127.

LOPEZ BELLO, S. E.; RÉGNIER, J C. Etnoestatística(s): uma nomeação histórica, pragmática e linguística da contemporaneidade. Revista Latinoamericana de Etnomatemática, v.10, n.3, 2017, p.111-128.

LÓPEZ. M. V. O conceito de experiência em Michel Foucault. Reflexão e Ação, Santa Cruz do Sul, vol.19, n. 2, p.42-55, jul./dez., 2011.

MARCELLO, F. A. Dispositivo da maternidade: mídia e produção agonística da experiência. 2003. 180f. Dissertação (Mestrado em Educação) - Programa de Pós-Graduação em Educação da Faculdade de Educação, Universidade Federal do Rio Grande do Sul, Porto Alegre, 2003.

MARCELLO, F. A. Sobre modos de produzir sujeitos e práticas na cultura: o conceito de dispositivo em questão. Currículo sem Fronteiras, v.9, n.2, p.226-241, jul/dez, 2009. Disponível em: http://www.curriculosemfronteiras.org/vol9iss2articles/marcello.pdf. Acesso em 13 ago. 2016.

MORO ABADÍA, O. Que es um dispositivo? Empiria: Revista de Metodología de Ciencias Sociales, n.26, p.29-46, 2003.

PINHO, P.M. Numeramentalização: olhares sobre os usos dos números e dos seus registros em jogos de práticas escolares na contemporaneidade. 2013. 198f. Tese (Doutorado em Educação) - Programa de Pós-Graduação em Educação da Faculdade de Educação, Universidade Federal do Rio Grande do Sul, Porto Alegre, 2013.

SANTAIANA, R. Educação integral no Brasil: a emergência do dispositivo da intersetorialidade. 2015. 188f. Tese (Doutorado em Educação) - Programa de Pós-Graduação em Educação da Faculdade de Educação, Universidade Federal do Rio Grande do Sul, Porto Alegre, 2015. 
SPERRHAKE, R. O dispositivo da numeramentalidade e as práticas avaliativas: uma análise da Avaliação Nacional da Alfabetização. 2016. 191f. Tese (Doutorado em Educação) - Programa de Pós-Graduação em Educação, Universidade Federal do Rio Grande do Sul, Porto Alegre, 2016.

TRAVERSINI, C.; BELLO, S. E. L. O numerável, o mensurável e o auditável: estatística como tecnologia para governar. Educação e Realidade, Porto Alegre, v.34, n.2, p.135-152, mai.-ago. 2009.

Recebido em fevereiro de 2019.

Aprovado em abril de 2019. 